\title{
Reproducing Citizens: Family, State, and Civil Society
}

\author{
edited by Sasha Roseneil, Isabel Crowhurst, \\ Ana Cristina Santos, and Mariya Stoilova \\ London and New York: Routledge (Taylor and Francis Group) 2016 \\ ISBN 978-1-138-94229-5 \\ Hardcover \$160, 106 pp.
}

\author{
Reviewed by Anthony C. Masi \\ Desautels Faculty of Management, McGill University
}

This short volume was originally published as a series of articles in Citizenship Studies, volume 17, issue 8 (December 2013), and the reader is informed that when this material is cited, the original page numbering should be used. In this review, however, for the sake of simplicity, I use the page numbers in the book when referring to the specific passages cited.

The twelve contributors to the seven chapters (including the editorial introduction) of this book come from the following fields of study: sociology, criminology, education, communications studies, psychology, history and contemporary studies, law, and social work. The chapters present case studies of various issues, dealing with the following countries: Mexico, Sweden, Italy (2), Australia, and the United Kingdom.

From this array of disciplines and geographic locales, the reader is invited to consider reproduction in relation to citizenship as these variables intersect with diverse dichotomies such as public/private, political/personal, rational/emotional, mind/body and with the "biological, sexual, and technological realities of natality" (p. 1). Thus, this is a book about citizenship, not about demography per se, but it does play nicely on the ambiguity of the term "reproducing": (i) creating new life, (ii) perpetuating social inequalities across groups and generations, and (iii) socializing individuals to expectations regarding rights and obligations, of which the ability to have children should be seen as fundamental to citizenship. In this regard, the editorial introduction plays the crucial role of providing the reader with sufficient background to appreciate the other contributions in the volume.

For demographers, two novel aspects of these chapters/articles will be (a) the categorization of different dimensions of citizenship (political, social, economic, multicultural, bodily, and intimate); and (b) framing the relationship between the citizenship and the state's regulation of reproduction through the promulgation of procreative standards that are not always available to citizens who do not fit the norm. While dealing with widely varying settings and alternative theoretical perspectives, the principal (and principle) concern of this volume is the extent to which reproductive self-determination has been, can be, or should be secured. In other words, the chapters in this book provide commentary (sometimes explicitly, sometimes implicitly) on population policies, laws, and other regulations, and on the impact that these norms have on citizens' participation, or lack thereof, in procreation.

In reading these chapters, the quantitatively-minded will be challenged to think about demographic variables without numbers and asked to appreciate the more qualitative aspects of the issues: abortion questions in Mexico (p. 12-27), motherhood for the transgendered in Sweden (p. 28-41), lack of access to assisted reproduction in Italy (p. 42-55), media representations and "reproductive vulnerabilities" of those from Australia who seek off-shore surrogacy (p. 56-69), Kurdish migrant women's attitudes and practices regarding motherhood in London (UK) (p. 70-84), and intergenerational relations within the biological family for non-straight individuals in (again) Italy (p. 85-99). 
Those who already have a strong qualitative orientation will read the chapters and immediately understand the saliency of the categorical questions raised by the authors; therefore, they would benefit by making the effort to assess the numerical import of the arguments, such as their actual or potential impact on population birth rates or on individual fertility. In both instances, approaching the studies from the perspective of the other should make the volume more enjoyable than just reading the words as written.

The individual chapters are comprehensible, but often the theoretical discussions are verbose, convoluted, and not always suitably linked to the empirical evidence presented for the case studies that form the backbone of each chapter. These articles/chapters do form a coherent narrative on the theme of citizenship and reproduction (in the three senses of the word noted above), thanks to the introductory essay by the editors and also to the fact that the authors of the chapters all cite directly, or draw on indirectly, the essay on citizenship, reproduction and the state by B.S. Turner (2008) or his earlier piece (2001) on the erosion of citizenship.

In summary, this edited volume (originally a special issue of Citizenship Studies) provides some thought-provoking ideas about natality and citizenship from theoretical and policy perspectives, but it is lacking the kind of demographic data that could actually inform or sustain the arguments that are made. These are analyses of numerators and the authors appear not to be interested in the associated denominators.

\section{References}

Turner, B.S. 2008. Citizenship, reproduction, and the state: international marriage and human rights. Citizenship Studies 12(1):45-54.

2001. The erosion of citizenship. The British Journal of Sociology 52(2):189-209. 